\title{
A STUDY OF ENDOIMETRIAL THICKNESS IN TRANS VAGINAL SONOGRAPHY IN RELATION WITH HISTOPATHOLOGY REPORT IN DILATION \& CURRATAGE IN AUB WOIMEN
}

KEY WORDS: Trans vaginal sonography, abnormal vaginal bleeding, dilation and curretage

\section{Dr. Mool Chand Khichar}

Dr. Bajarang Lal Rar*

\section{Assistant Professor In Obstetrics And Gynae At Spmc,bikaner}

Senior Specialist In Obstetrics And Gynae At Sk Hospital Sikar *Corresponding Author

A study of of endometrial thickness on TVS in relation with histopathology report on dilation and curettage.

AIM AND OBJECTIVE-To set a cut off limit of endometrial thickness on TVS for differtiating between normal and abnormal endometrium.

MATERIAL AND METHOD-hospital based comparative study.

RESULTS-TVS is non invasive, simple first line procedure in AUB women. Mean endometrial thickness in normal endometrial group was $8.00 \pm 2.44 \mathrm{~mm}$ and in abnormal endometrial group was $15.16 \pm 33 \mathrm{~mm}$. The difference was found highly significant $(\mathrm{p}$ value $<.001)$

\section{INTRODUCTION-}

Abnormal uterine bleeding (AUB) is a common problem which account for more than one fifth of all visits to outpatient door and more than one fourth of all hysterectomies ${ }^{1,2}$ .Abnorma 1 uterine bleeding is excessive, prolonged, unexpected or acyclic bleeding regardless of cause or diagnosis, not only affects the quality of life such as intimate relationships, day to day living but can have serious adverse consequences like anemia or malignancy. Abnormal peri menopausal bleeding should always be taken seriously and properly investigated, no matter how minimal or persistent .Perimenopause" include the period immediate prior to menopause (when the endocrinological, biological and clinical feature of approaching menopause commences )and first year after menopouse. Evaluation of abnormal uterine bleeding in perimenopause women is challenging because waxing and waning function of ovary produces change in the ministration pattern .Durin last decade various methods to perimenopausal bleeding evaluation are transvaginal sonography (TVS), endometrial biopsy, dilatation\&curettage and hysteroscopy.Diagnostic procedures obtaining material for histopathlogy assessment (e.g.D\&C, ,hysteroscopy,and endometrial biopsy )can be more accurate but are also more invasive and need anesthesia.TVS is simple method of visualization of clear endomerium. TVS can be safely used as an initial investigation in the management of AUB as it a non invasive method for detection of endometrial pathology with no need of anesthesia. ${ }^{3.4}$ No need of full urinary bladder as compared to trans abdominal USG .TVS is prefferd in obese patients, patients with extensive anterior abdominal wall scarring and retroverted uterus. Thus, currently available modalitie $s$ are far from being perfect ${ }^{4}$. Ability of TVS for screening the lesions within the endometrial cavity is limited. The finding of a thickened central endometrial complex seen on TVS is often non-specific and may be caused by an endometrial polyp,submucosal fibroids, endometrial hyperplasia, carcinoma, or cystic atrophy. Focal lesions are underdiagnosed at TVS because of limitations of the doublelayer thickness evaluation ${ }^{5}$ Disadvantages of TVS -Limited transducer movements inside the vagina,Absence of sound enhancement as seen withthe filled urinary bladder in transabdominal sonography Unable to distinguish between benign proliferation, hyperplasia, polyp and malignancy ${ }^{6}$.

\section{AIM AND OBJECTIVE-}

1. Set a relation endometrial assessment by TVS with histopathology report obtained by D\&C.

2. Deciding a cut off limit of endometrium thickness to reduce unnecessary diagnostic invasive curettage and hysteroscopy procedure.

\section{MATERIAL AND METHOD-}

The present study was conducted in department obstetrics \& gynecology, zenana hospital attached to s.m.s,medical college,jaipur .Study period was 2012-13 Case collection :OPD and indoor cases taken.A total of fourty cases were taken.

\section{INCLUSION CRITERIA-}

Any patient above the age of fourty yrs with history of abnormal uterine bleeding.

\section{EXCLUSION CRITERIA-}

Women taking medical treatment like hormonal pills.All eligible patients were examined by taking detailed history about her age ,parity, menustration pattern(present and past ) including duration, severity, cyclic or acyclic, method of contraception used or any other medical and gynecological problem. All routine investigations like cbc , coagulation profile done. Then all patients were subjected to TVS.TVS was performed using vaginal transducer of $6.5 \mathrm{MHZ}$ frequency.Endometrial thickness measured at the thickest part of endometrium from the endometrial-myometrial junction reflective interface at the funds in the longitudinal plane .The thickness measured includes both endometrial layers. Then all patients were subjected to D\&C and result Were analysed.

\section{OBSERVATIONS-}

TABLE-1DISTRIBUTION OF CASES ACCORDING HPR FINDING ON DILATION \& CURRATAGE

\begin{tabular}{|c|c|c|c|}
\hline \multicolumn{2}{|c|}{ Condition of endometrium } & \multicolumn{2}{c|}{ Patients } \\
\cline { 3 - 4 } Normal & Atrophic endometrium & 0 & 0 \\
\cline { 2 - 4 } & Proliferative endometrium & 23 & 57.5 \\
\cline { 2 - 4 } & Secretary endometrium & 11 & 27.5 \\
\hline Abnormal & Endometrial Hyperplasia & 5 & 12.5 \\
\cline { 2 - 4 } & Polypoid endometrium & 1 & 2.5 \\
\cline { 2 - 4 } & Carcinoma & 0 & 0 \\
\hline
\end{tabular}

$57.5 \%$ cases had proliferative phase while $27.5 \%$ had secretary phase, $12.5 \%$ cases had endometrial hyperplasia, $2.5 \%$ cases had polypoidal endometrium.

TABLE-2 DISTRIBUTION OF CASES ACCORDING ENDOMETRIUM THICKNESS IN RELATION WITH NORMAL AND ABNORMAL UTERUS

\begin{tabular}{|l|l|l|l|l|l|}
\hline \multicolumn{2}{|l|}{ Condition of Endometrium } & No. & Range & Mean & SD \\
\hline $\begin{array}{l}\text { Perimenopausal } \\
\text { group }\end{array}$ & Normal type & 34 & $5-16$ & 8.00 & 2.44 \\
\cline { 2 - 6 } & Abnormal type & 6 & $11-19$ & 15.16 & 3.3 \\
\hline
\end{tabular}


In perimenopausal women mean endometrial thickness of normal endometrium was $8.00 \pm 2.44$ andMean endometrial thickness of abnormal endometriam was $15.16 \pm 3.3$.The difference between mean normal and abnormal endometrium thickness was significance ( $p$ value $<.001$ ).

\section{DISSCUSSION-}

Alywaya a ideal diagnostic test should be non invasive, easily acceptable ,easly performable, low costaly,high sensitivity ,high specificity. In this prospective study we done study of endometrium on TVS \& its relation with HPR finding on D\&C.HPR was normal in $85 \%$ cases,endometrial hyperplasia in $12.5 \%$ and polyp. in $2.5 \%$ cases. A. singh ${ }^{7}$, S. singh, V. M., K. singh (2001)have done astudyins.m. medicalcollege, Agra,India. 100 patients, out of which 50 were of DUB and 50 of reproductive age group with normal menstrual cycles were for the study. On histopathology normal endometrium was present in $60 \%$ cases, endomentrial hyperplasia was in $28 \%$ cases. Histopathological findings were well correlated with TVS findings in all cases except four. ${ }^{7}$ Mean endometrial thickness in normal endometrium group was $8.00 \pm 2.44 \mathrm{~mm}$ and in abnormal endometrium group was $15.16 \pm 33 \mathrm{~mm}$. The difference was found highly significant $(\mathrm{p}$ value $<.001)$. Similar results obtain by Thera ${ }^{8}$ and co workers suggested that endometrial thickness of $<7 \mathrm{~mm}$ gave $100 \%$ sensitivity and $46 \%$ specificity with normal histopathology. Simillar results also found by Odvaar. et $\mathrm{al}^{9}$ study In premenopausal women $>8$ mmendometrial thickness gave sensitivity of $67 \%$, Specificity $75 \%$, positive predictive value $14 \%$ and negative predictive value $97 \%$.

\section{CONCLUSION-}

This study shows that in perimenopausal women with abnormal uterine bleeding the first investigation should be less invasive TVS. If endometrial thickness with $>8 \mathrm{~mm}$ on TVS then they can be further subjected to dilatation and curettage, as this study shows that with en endometrial thickness Cut off of $>8 \mathrm{~mm}$ the dilatation and curettage can be avoided in fourty percentageAUB women. . If necessary we can subject women to further more invasive tests like hysteroscopic guided biopsy, saline infusion sonogram. In TVS we can also see the myometrium, endomyometrial junction, adnexa more precisely.

\section{REFERENCES}

1- Mencaglia L, Perino A, Hamou J. Hysteroscopy in perimenopausal and postmenopausal women with abnormal uterine bleeding. J Reprod Med., 1987;32(8):577-822.

2. O'Connor, V. M. Heavy menstrual loss: Part 1. Is it really heavy loss? Medicine Today, 2003; 4(4):51-59.

3. Vitner D, Filmer S, Goldstein I, Khatib N, Weiner Z. A comparison between ultrasonography and hysteroscopy in the diagnosis of uterine pathology. European Journal of Obstetrics \& Gynaecology and Reproductive Biology, 2013;171(1): 143- 145 .

4. Dreisler E, Poulsen LG, Antonsen SL, Ceausu I, Depypere H, Erel CT, et al EMAS clinical guide: assessment of the endometrium in peri and postmenopausal women. Maturitas, 2013;75:181-190.

5. Aslam M, Ijaz L, Tariq S, Shafqat K, Meher-Un-Nisa, Ashraf R, et al. Comparison of transvaginal sonography and saline contrast sonohysterography in women with abnormal uterine bleeding: correlation with hysteroscopy and histopathology. Int J Health Sci (Qassim), 2007; 1(1): 17-24

6. Vitner D, Filmer S, Goldstein I, Khatib N, Weiner Z. A comparison between ultrasonography and hysteroscopy in the diagnosis of uterine pathology. European Journal of Obstetrics \& Gynaecology and Reproductive Biology, 2013;171(1):143-145.

7. Anjali singh, Saroj singh, Veena mathur, Kalpana Singh ; TVS in DUB and its correlation with histopathology;Journal of obstetrics and gynecology of India, 2001;51(6): 116-116

8. Tong Song Theera. Md. Chailert Pongnarisorn, M.D And Pongsak Mahanuphap, M.D., "Use of Vagino sonographic measurement of Endomentrial thickness in the identification of Abnormal Endometrium in Perimenopausal and Post Menopausal bleeding", J.Clin Ultrasound, 1994 ; 22:479-482.

9. Smith Peter, Oddvar Bakus, Gun Heimer and Ult Ulmsten, “ Transvaginal Ultrasound for identifying endometrial abnormality" Acta obstet \& Gynaecol scand, $1991 ; 70: 592-594$ 